\title{
Concrete-to-concrete bond strength. Influence of the roughness of the substrate surface is
}

\author{
Eduardo N.B.S. Júlio ${ }^{\text {a,* }}$, Fernando A.B. Branco ${ }^{b}$, Vítor D. Silva ${ }^{\text {a }}$ \\ ${ }^{a}$ Department of Civil Engineering, Faculty of Science and Technology, University of Coimbra Portugal \\ ${ }^{\mathrm{b}}$ Department of Civil Engineering, Instituto Superior Técnico, Technical University of Lisbon, Portugal
}

Received 24 January 2004; received in revised form 6 April 2004; accepted 8 April 2004

Available online 17 June 2004

\begin{abstract}
An experimental study was performed to evaluate the bond strength between two concrete layers, for different techniques for increasing the roughness of the substrate surface. In a total of 25 slant shear specimens and 25 pull-off specimens the substrate surface was prepared by wire-brushing; sand-blasting; chipping with a light jackhammer; or were left as-cast against steel formwork. Three months later, the new concrete was added. Pull-off tests were performed to evaluate the bond strength in tension. Slant shear tests were conducted to quantify the bond strength in shear. Analysis of results indicated that: the highest value of bond strength was achieved with sand-blasting; pull-off tests are adequate to estimate the bond strength in situ; and pre-wetting the substrate surface does not seem to influence the bond strength.
\end{abstract}

(c) 2004 Elsevier Ltd. All rights reserved.

Keywords: Concrete; Roughness; Bond; Strength

\section{Introduction}

Some techniques for repairing and/or strengthening structures involve adding new concrete to an existing concrete substrate. The common practice consists of first increasing the roughness of the substrate surface. Several methods are used but little information is available on the relative efficiency of each one.

Concrete jacketing, for example, is one of the most commonly used strengthening techniques for structural elements, such as reinforced concrete (RC) columns. The need to prepare the substrate surface is referred to in all the published works on this subject [1]. Bett et al. [2] performed an experimental study on RC columns

\footnotetext{
Research significance: The information presented in this paper helps engineers to choose, based on experimental results instead of empirical judgment, the best technique for increasing the surface roughness of a concrete substrate, in order to achieve the best bond strength between the latter and an added new concrete layer.

* Corresponding author.

E-mail address: eduardo@dec.uc.pt (E.N.B.S. Júlio).
}

repaired and strengthened by jacketing, in which they mention that all models were roughened by light sandblasting before jacketing. Alcocer and Jirsa [3] studied the behavior of RC connections redesigned by jacketing. They indicate that the outermost concrete aggregate was exposed using a chipping hammer. Following this research work, Alcocer [4] conducted more experimental tests using the same surface treatment but followed by removal of small particles and dust using a thick brush and a vacuum cleaner. Ramirez et al. [5] conducted experimental research on the repair of RC columns with partial localized damages. In this study the concrete surfaces and the exposed parts of the reinforcing bars of all columns to be repaired were brushed with a stiff wire brush. Rodriguez and Park [6] tested RC columns strengthened by jacketing and subjected to simulated seismic loading. The surface of the as-built columns had been lightly roughened by chipping before the jackets were placed. Stoppenhagen et al. [7] tested severely damaged concrete frames repaired and strengthened by jacketing. In this case the spandrels were roughened with an electric concrete hammer. 
In spite of the unanimous reference to the importance of achieving a good bond between the original column and the jacket, crucial to ensure a monolithic behavior of the composite element, the bond strength, reached with the adopted methods of surface preparation, has not been quantified.

There are also some published works on bonding of repair materials to a concrete substrate where the preparation of the substrate surface with different techniques is mentioned. However, differences are observed on: the adopted tests; the concrete mix of the substrate; the repair materials; the age of the specimens; the temperature and relative humidity conditions; the eventual use of bonding agents, etc., For these reasons, conclusions presented are not usually coincident and sometimes findings are contradictory.

Surface treatment with jack hammers is current practice in many countries for removing the unhealthy layer of concrete substrate but there is a generalized opinion that this method promote substrate damage causing micro-cracking which results in interface weakness [8-11]. However, Talbot et al. [12] obtained good results with a combination of the latter technique followed by sand-blasting. Abu-Tair et al. [11] indicate that the needle-gun method of surface preparation is very similar in action to electric and pneumatic hammers as it seems to promote damage to the substrate.

Sand-blasting and water-jetting are the best surface preparation methods according to several authors $[8,9,12-14]$. In spite of that, contradictory conclusions are reported. Talbot et al. [12], referring to a study performed by Felt, indicate that this author obtained poor results with sand-blasting which was attributed to the polishing effect caused by this technique. However, Talbot et al. conducted their own experimental research and the highest strengths were obtained with this method.

Other procedures are referred to in the literature such as grinding; wire-brushing; shot-blasting; etc., Talbot et al. [12] indicate that low bond strengths were obtained with substrate surfaces treated by grinding. However, Saucier and Pigeon [10] state that tests conducted on glass-like polished surfaces showed that the resulting adhesion is high. Chemical products are also used to increase the substrate surface roughness. Austin et al. [14] mention that Cleland and and Long used an acid etching method to prepare the bond surface, but found it difficult to ensure that all residues are cleaned from surface.

In relation to pre-wetting the substrate surface, opinions diverge about the most appropriate situation. Even in codes of practice recommendations are contradictory. Saucier and Pigeon [10] make reference to the AASHTO-AGC-ARTBA Joint Committee that recommends a dry surface of concrete, except in dry and hot summer days, and the Canadian Standards
Association Standard A23.1 that recommends wetting the surface for at least $24 \mathrm{~h}$ before casting the new concrete.

Emmons [13] mentions that the moisture level of the substrate may be critical in achieving bond. He states that an excessively dry substrate may absorb too much water from the repair material while excessive moisture in the substrate may clog the pores and prevent absorption of the repair material. Therefore, a saturated substrate with a dry surface is considered to be the best solution. Austin et al. [14] mention that Chorinsky concluded that too dry or too wet surface of concrete substrate always results in weak bond strength of the interface. Saucier and Pigeon [10] state that wetting the substrate surface did not influence the durability of bond made with low W/C pastes as bonding agents, but improved the durability of those made with high W/C pastes. Silfwerbrand [9] mention that, following the recommendations of the Swedish National Road Administration, the tested slabs were wetted and kept moist for $48 \mathrm{~h}$ before casting the overlay and that the surface was dry when the latter was placed. Cleland and Long [15] considered four moisture conditions and indicate that, for laboratory dry condition and saturated substrate/surface dry condition, results were similar while, for oven dry condition and saturated substrate/surface wet condition, lower bond strengths were achieved. Talbot et al. [12] report that pre-wetting the surface before applying the new concrete layer is common practice although.

This paper presents the results of slant shear tests and pull-off tests performed to quantify the bond strength between two concrete layers, using the techniques most commonly used in practice for increasing the roughness of the substrate surface. Three months after the concrete substrate was cast, the new concrete was added. Twenty eight days later, slant shear tests and pull-off tests were performed. Bond strength was evaluated, both in shear and in tension.

\section{Experimental investigation}

The experimental study had the main purpose of quantifying the influence of the surface roughness of the concrete substrate on the bond strength between this and the added new concrete. A supplementary objective was to investigate the influence of the substrate moisture condition.

The tests selected for the study, were the slant shear test (Fig. 1) and the pull-off test (Fig. 2). The first one is a shear test and has been selected for being sensitive to roughness according to different researchers [11,13, $16,17]$. The adopted geometry for the slant shear specimens was a $0.20 \times 0.20 \times 0.40 \mathrm{~m}^{3}$ prism with the interface line at $30^{\circ}$ to the vertical. The specimens were tested 


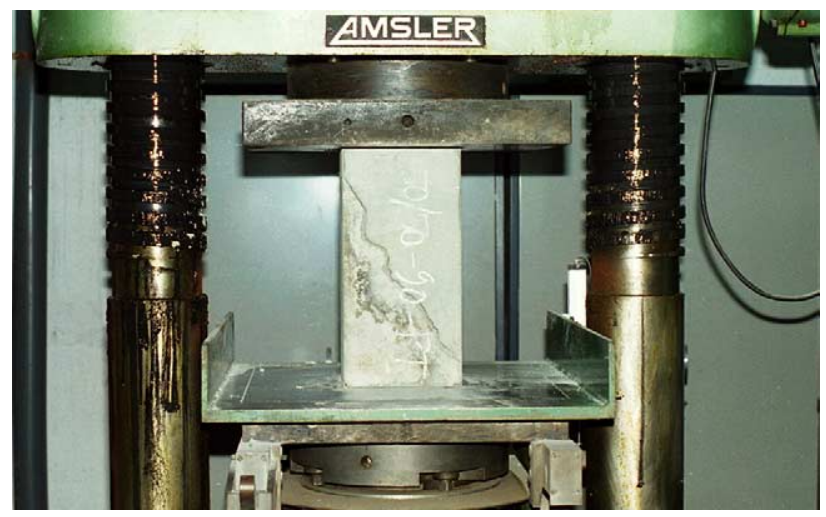

Fig. 1. Slant shear test.

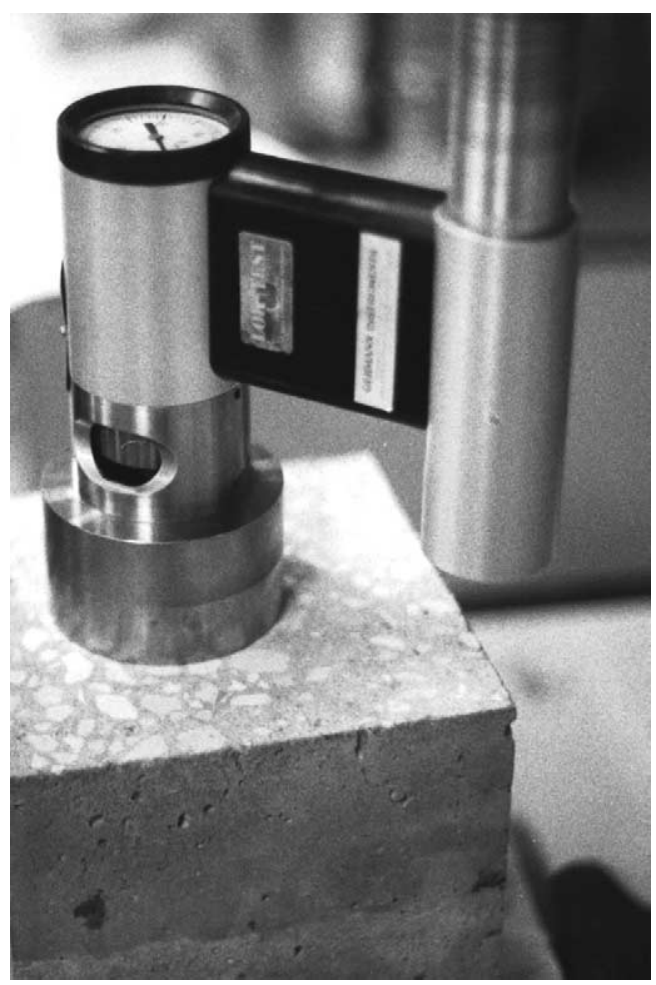

Fig. 2. Pull-off test.

under compression using the standard procedure for the testing of cubes or cylinders for compressive strength.

The pull-off test is a tension test and has been chosen for two reasons: (1) to evaluate the bond strength in tension of the interface; and (2) because it can be carried out in situ $[8,18]$. Consequently, another objective of this study was to investigate the possibility of correlation between both tests, which would represent an obvious advantage.

The adopted geometry for the pull-off specimens was a $0.20 \mathrm{~m}$ cube with the interface line at the middle. A core of $75 \mathrm{~mm}$ diameter was drilled into the added concrete and extending $15 \mathrm{~mm}$ beyond the interface into the substrate. A circular steel disc was bonded, with an epoxy resin, to the surface of the core. A tension force was applied to the disc, with a commercial device at a steady rate of $0.05 \mathrm{MPa} / \mathrm{s}$, until failure occurred.

Besides the surface roughness, all parameters that could influence the bond strength were kept constant: the concrete substrate mix; the added concrete mix; and their ages. In order to define them, preliminary tests were conducted [16].

The results of a first set of tests indicated that, if the compressive strength of the added concrete is significantly higher than that of the concrete substrate, a monolithic rupture mode may occur. With the results of a second set of tests, it was concluded that bond strength seems to decrease with an increase in the difference between the age of the added concrete and the age of the concrete substrate. A third set of tests revealed that, considering the same mix for the concrete substrate and the added concrete, and the same age difference between them, bond strength seems to increase with increasing concrete compressive strength, tending to the rupture force of monolithic specimens.

Taking into account the results of these preliminary tests, a concrete mix with $50 \mathrm{MPa}$ estimated compressive strength was adopted for both the substrate and the added concrete. The constituents of this concrete were $\left(/ \mathrm{m}^{3}\right) 360 \mathrm{~kg}$ of type I:32.5 Portland cement, 1.61 of a modified lignosulphonate admixture, 1681 of water, $813 \mathrm{~kg}$ of siliceous sand with 2.84 fineness modulus, 469 $\mathrm{kg}$ of limestone crushed aggregates with 6.16 fineness modulus and $567 \mathrm{~kg}$ of limestone crushed aggregates with 6.93 fineness modulus.

At the time of the test, the original concrete age and the added concrete age were set, respectively, at 112 and 28 days. For each variable, 5 slant shear specimens and 5 pull-off specimens were constructed as well as 6 standard specimens to characterize the compressive strength of the concrete substrate and of the added concrete (3 cubes for each). Due to the non-existence of temperature and relative humidity controlled conditions in the laboratory, there has also been a concern to cast the first halves and the second halves of specimens of all situations during short periods of time, April/May and July/August, respectively.

The adopted roughening techniques were those most commonly used in practice. The following situations have been considered:

(1) surface cast against steel formwork (to serve as reference);

(2) surface prepared with steel brush (Fig. 3);

(3) surface partially chipped (Fig. 4);

(4) as in (3) plus water saturation $24 \mathrm{~h}$ prior to concrete cast; and

(5) surface treated with sand-blasting (Fig. 5).

Situation (4) was considered to analyze the advantage of pre-wetting the original concrete surface before casting the new concrete. 

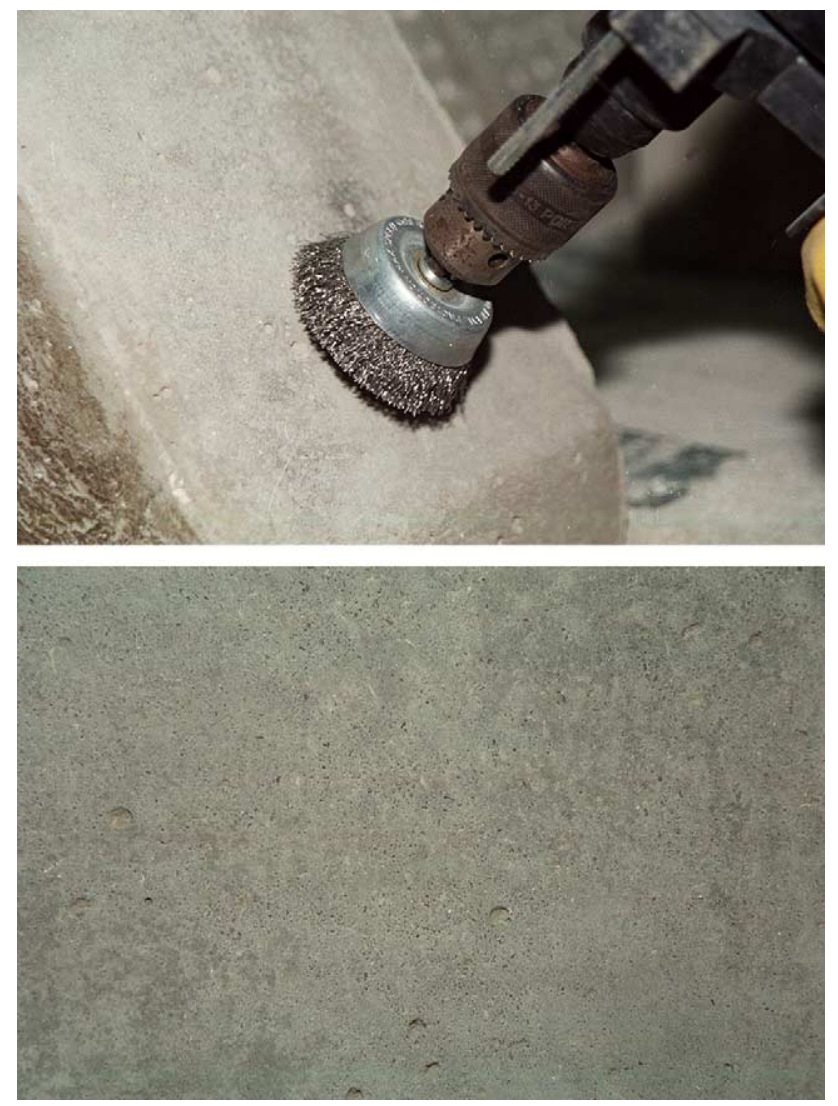

Fig. 3. Substrate surface prepared with steel brush.

The following objectives were defined for this experimental research: (1) to quantify the influence of the substrate surface roughness on the bond strength; (2) to analyze the influence of pre-wetting the substrate surface on the bond strength; and (3) to examine the correlation between the bond strength in shear, obtained with the slant shear test, and the bond strength in tension, evaluated with the pull-off test, of the joint.

\section{Results and discussion}

In Table 1 are presented the average values obtained with tests performed on standard specimens to evaluate the compressive strength of the original concrete and of the added concrete, used in all 5 situations. In Table 2, the average value of the bond strength in shear, determined with the slant shear test, is given for each of those situations and, in Table 3, the corresponding average value of the bond strength in tension, measured with the pull-off test, is indicated. It should be mentioned that the failure mode, observed in all specimens, tested with both methods, was always an adhesion failure at the interface.

In Table 3, the value of the bond strength in tension, determined with the pull-off test, is not indicated for the
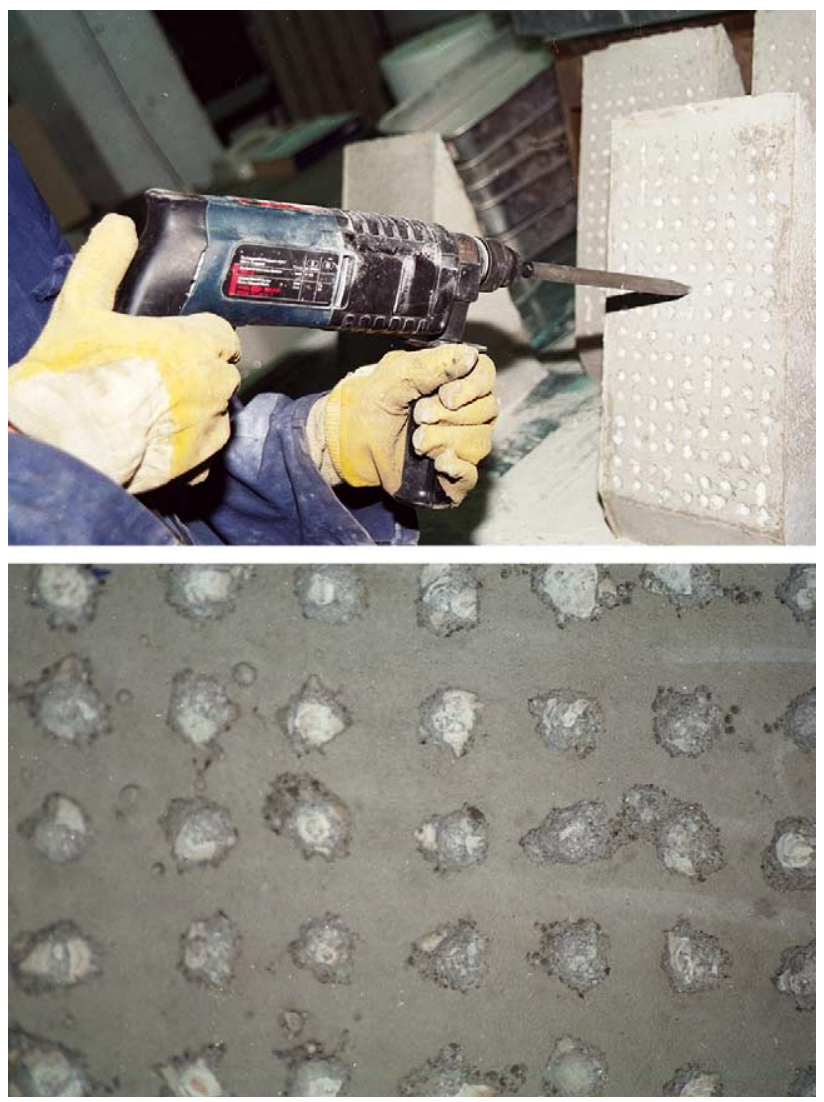

Fig. 4. Substrate surface partially chipped.

first situation, due to the fact that, when drilling the core, de-bonding occurred for all the 5 specimens.

Since the adopted concrete mix was the same for both halves of all specimens and the selected materials were also the same, the difference between the compression strength values can only be explained by the differences of temperature and relative humidity registered in the laboratory between the periods April/May and July/ August. Nevertheless, the conclusions drawn subsequently are not compromised since the difference between the compressive strength of the substrate and of the added concrete is almost the same for all situations considered.

In Fig. 6, a chart with the average value of the bond strength in shear, obtained with the slant shear test, is presented. In Fig. 7, the average value of the bond strength in tension, measured with the pull-off test, and the analytically determined average value of the tensile strength of the added concrete are given. Also presented, in Fig. 8, is a linear trend line that correlates the average values obtained with the slant shear test with the corresponding average values measured with the pull-off test for each of the five mentioned situations.

The situation of substrate surface left as-cast against steel formwork (1), considered to serve as reference, presented the lowest value of bond strength in shear and 

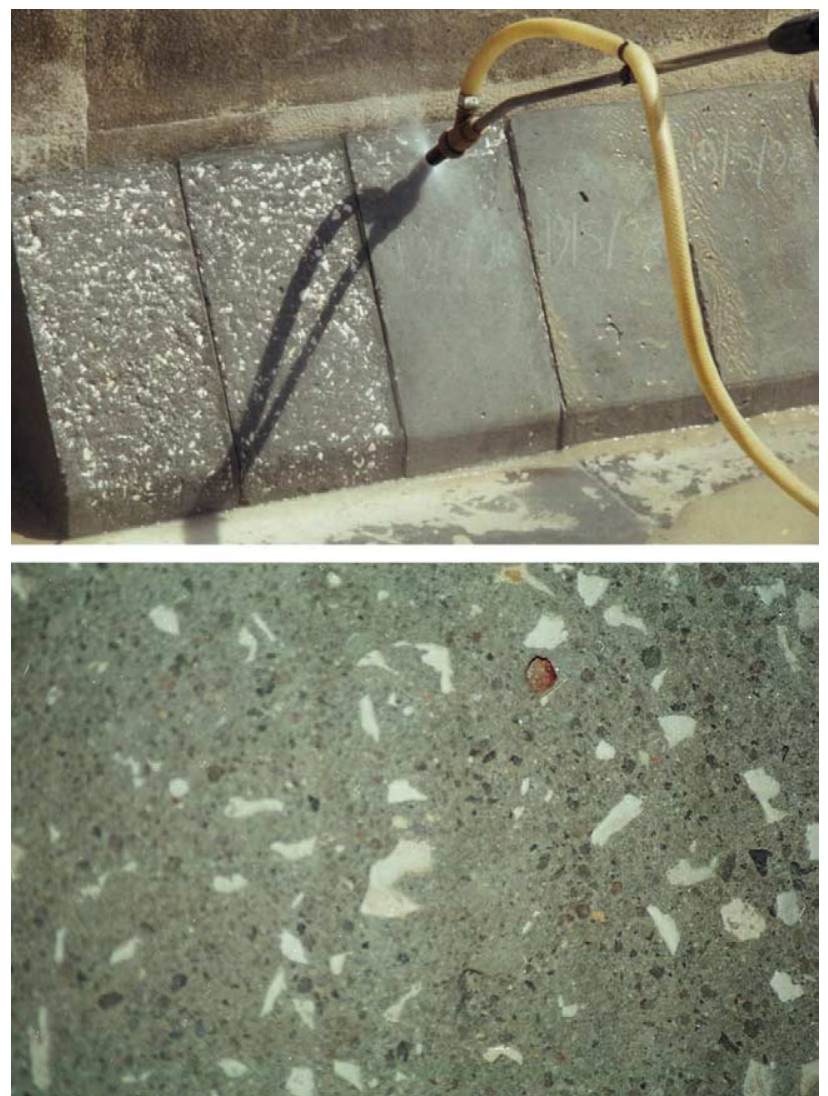

Fig. 5. Substrate surface treated with sand-blasting.

Table 1

Concrete compressive strength

\begin{tabular}{llll}
\hline $\begin{array}{l}\text { Situations } \\
\text { considered }\end{array}$ & $\begin{array}{l}\text { Substrate surface } \\
\text { treatment }\end{array}$ & $\begin{array}{l}\text { Compressive strength } \\
\text { (MPa) of }\end{array}$ \\
\cline { 2 - 4 } & $\begin{array}{l}\text { Substrate } \\
\text { concrete }\end{array}$ & $\begin{array}{l}\text { Added } \\
\text { concrete }\end{array}$ \\
\hline 1 & $\begin{array}{l}\text { As-cast against steel } \\
\text { formwork }\end{array}$ & 50.95 & 47.42 \\
2 & Wire-brushing & 49.66 & 46.11 \\
3 & $\begin{array}{l}\text { Partially chipped } \\
4\end{array}$ & 51.40 & 45.46 \\
5 & $\begin{array}{l}\text { Partially chipped } \\
\text { and pre-wetted }\end{array}$ & 52.90 & 45.71 \\
\hline
\end{tabular}

Table 2

Slant shear test results

\begin{tabular}{llcc}
\hline $\begin{array}{l}\text { Situations } \\
\text { considered }\end{array}$ & $\begin{array}{l}\text { Substrate surface } \\
\text { treatment }\end{array}$ & $\begin{array}{l}\text { Bond strength } \\
\text { in shear }(\mathrm{MPa})\end{array}$ & $\begin{array}{l}\text { Variation co- } \\
\text { efficient }(\%)\end{array}$ \\
\hline 1 & $\begin{array}{l}\text { As-cast against } \\
\text { steel formwork }\end{array}$ & 1.30 & 33.85 \\
2 & Wire-brushing & 10.67 & 8.90 \\
3 & Partially chipped & 6.24 & 20.67 \\
4 & Partially chipped & 6.64 & 13.10 \\
5 & and pre-wetted & & \\
5 & Sand-blasting & 14.13 & 8.56 \\
\hline
\end{tabular}

in tension. The situation of surface partially chipped (3) led to values of bond strength in shear and in tension higher than the latter situation but considerably lower
Table 3

Pull-off test results

\begin{tabular}{lllc}
\hline $\begin{array}{l}\text { Situations } \\
\text { considered }\end{array}$ & $\begin{array}{l}\text { Substrate surface } \\
\text { treatment }\end{array}$ & $\begin{array}{l}\text { Bond strength in } \\
\text { tension (MPa) }\end{array}$ & $\begin{array}{l}\text { Variation } \\
\text { coefficient } \\
(\%)\end{array}$ \\
\hline 1 & $\begin{array}{l}\text { As-cast against } \\
\text { steel formwork }\end{array}$ & - & - \\
& Wire-brushing & 1.92 & 13.54 \\
3 & Partially chipped & 1.47 & 7.48 \\
4 & Partially chipped & 1.02 & 12.75 \\
5 & and pre-wetted & & \\
\hline
\end{tabular}

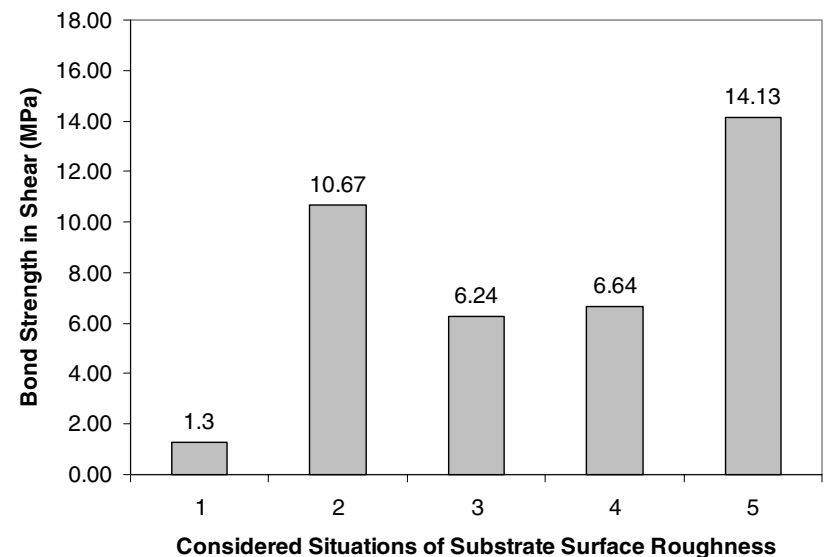

Fig. 6. Slant shear test results.

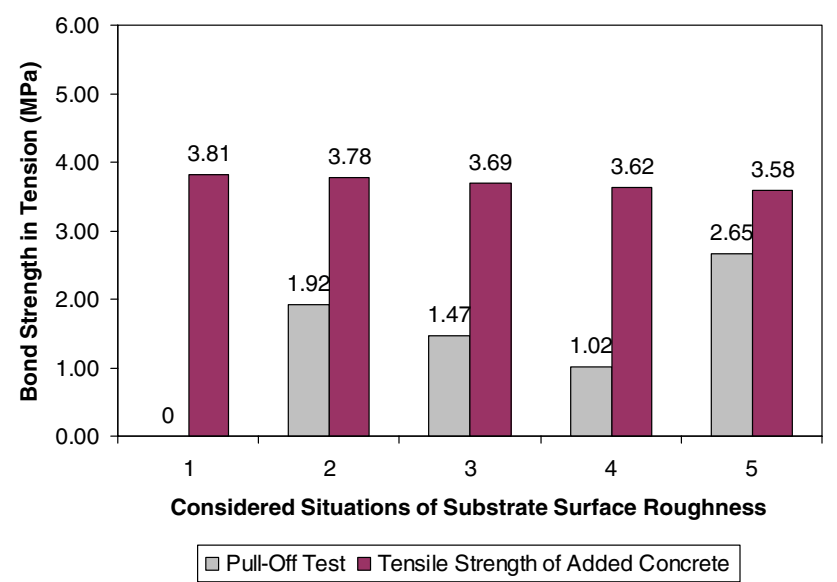

Fig. 7. Pull-off test results.

than the remaining situations. This result can be explained since only the corners of a $20 \mathrm{~mm}$ grid were chipped, as it can be observed in Fig. 4, and most of the substrate surface was not treated. The situation of surface prepared with wire brush (2) presented relatively high values of bond strength in shear and in tension, although the obtained surface texture was not very rough, i.e. the aggregates were not exposed. The last 


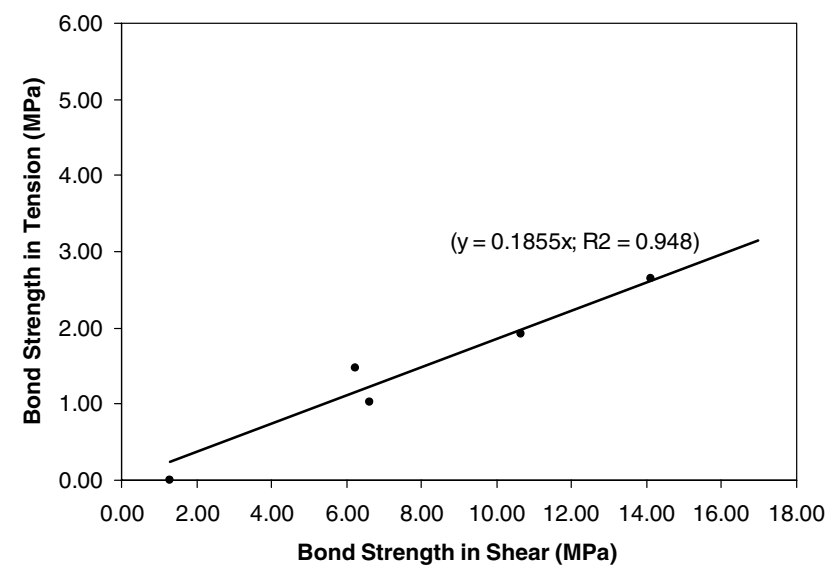

Fig. 8. Correlation between slant shear test and pull-off test results.

situation considered, surface prepared with sand-blasting (5), revealed the highest values of bond strength in shear and in tension. With this latter treatment, the surface texture obtained is not excessively rough either, but the aggregates are exposed.

The first objective of this study was achieved and it is possible to order the roughening techniques used from the highest value to the lowest: (5) sand-blasting, (2) wire-brushing, (3) partially chipped and (1) as-cast. The second purpose defined was to study the influence of pre-wetting the substrate surface on the bond strength. Taking into account only the results from the slant shear tests of situations (2) and (3) these seem to indicate that this variable does not have a significant influence. Considering the results from the pull-off test, the difference observed between these two situations is not negligible. However, there is a strong possibility that this difference is inherent to the test itself. It would be necessary to investigate this aspect alone in a separate study. The third and last objective was to verify if the results obtained with the slant shear test may be correlated with those reached with the pull-off test. Qualitatively that correlation is evident. Quantitatively it seems reasonable, presenting a trend line (Fig. 8) with a correlation coefficient of 0.948 .

The variation coefficients determined for the two adopted types of test were also analyzed, function of the substrate surface treatment. With the slant shear test, this factor decreases with the shear strength increase (Table 2). In fact, specimens of the first situation not only presented the lowest values of bond strength in shear $(1.30 \mathrm{MPa})$ as they presented the highest values of variation coefficient $(33.85 \%)$. Inversely, the specimens with the substrate surface treated with sand-blasting showed the highest values of bond strength in shear $(14.13 \mathrm{MPa})$ and the lowest values of variation coefficient $(8.56 \%)$. The pull-off test results are inconclusive on this subject. However, it seems that the sand-blasting treatment is the one that leads to the best results either in terms of bond strength or in terms of reliability.

\section{Summary and conclusions}

Sand-blasting was the preparation method of the substrate surface that presented the highest values of bond strength in shear and in tension, from all the considered techniques.

In relation to the influence of pre-wetting the substrate surface, results seemed to indicate that its effect is not significant.

A good correlation between the slant shear test results and the pull-off test results has been observed, validating the use of the latter test to evaluate in situ the bond strength between different concrete layers.

\section{Acknowledgements}

We are grateful to SIKA, HILTI, BETÃO LIZ, FIVINTE, DYWIDAG, PREGAIA, CIMPOR and SECIL for their collaboration in this research project.

\section{References}

[1] Júlio ES, Branco F, Silva VD. Structural rehabilitation of columns using reinforced concrete jacketing. Prog Struct Engng Mater 2003;5:29-37.

[2] Bett BJ, Klingner RE, Jirsa JO. Lateral load response of strengthened and repaired reinforced concrete columns. ACI Struct J 1988;85(5):499-508.

[3] Alocer S, Jirsa J. Assessment of the response of reinforced concreate frame connections redesigned by jacketing. In: Proceedings of the Fourth US National Conference on Earthquake Engineering. vol. 3. May; 1990. p. 295-304.

[4] Alcocer SM. RC frame connections rehabilitated by jacketing. J Struct Eng 1993;119(5):1413-31.

[5] Ramírez JL, Bárcena JM, Urreta JI, e Sánchez JA. Repair of concrete columns with partial localized damages. Report T 2.1 and 2.2 BREU-0186-C, April 1991.

[6] Rodriguez M, Park R. Seismic load tests on reinforced concrete columns strengthened by jacketing. ACI Struct J 1994;(MarchApril):150-9.

[7] Stoppenhagen DR, Jirsa JO, Wyllie Jr LA. Seismic repair and strengthening of a severely damaged concrete frame. ACI Struct J 1995;(March-April):177-87.

[8] Hindo KR. In-place bond testing and surface preparation of concrete. Concrete Int 1990;(April):127-9.

[9] Silfwerbrand J. Improving concrete bond in repaired bridge decks. Concrete Int 1990;(September):121-6.

[10] Saucier F, Pigeon M, Durability of new-to-old concrete bonding. In: Proceedings of the ACI International Conference Evaluation and Rehabilitation of Concrete Structures and Innovations in Design, Hong Kong. vol. 1. 1991. p. 689-707.

[11] Abu-Tair AI, Rigden SR, Burley E. Testing the bond between repair materials and concrete substrate. ACI Mater J 1996;(November-December):553-8. 
[12] Talbot C, Pigeon M, Beaupré D, Morgan DR. Influence of surface preparation on long-term bonding of shotcrete. ACI Mater J 1994;(November-December):560-6.

[13] Emmons PH. Concrete Repair and Maintenance. In: Part Three: Surface Repair, Section 6: Bonding Repair Materials to Existing Concrete. MA: R.S. Means Company; 1994. p. 154 63.

[14] Austin S, Robins P, Pan Y. Tensile bond testing of concrete repairs. Mater Struct 1995;28:249-59.

[15] Cleland DJ, Long AE, The pull-off test for concrete patch repairs. In: Proceedings of the Institution of Civil
Engineers - Structures and Buildings. vol. 122. November 1997. p. 451-60.

[16] Júlio ES. The influence of the interface on the behavior of RC columns strengthened by jacketing. PhD Thesis, University of Coimbra: 2001 [in Portuguese].

[17] Rizzo EM, Sobelman MB. Selection criteria for concrete repair materials. Concrete Int 1989;(September):46-9.

[18] Long AE, Murray AMcC. The pull-off partially destructive test for concrete. In: Malhotra VM, editor. In situ/nondestructive testing of concrete SP-82. American Concrete Institute; 1984. p. $327-50$. 